\title{
Ler e escrever: um direito de todos
}

Cleomar Azevedo

\section{RESUMO}

Há muitas décadas as inúmeras reprovações e a evasão escolar, ocorridas em especial no momento de aprendizagem da leitura e da escrita, têm sido uma temática apontada como uns dos mais graves problemas do ensino fundamental. O processo de alfabetização, que mesmo com as mudanças ocorridas no sistema de ensino, ainda mantém um alto índice de alunos que não aprendem a ler e escrever, continua a ser uma preocupação para o sistema escolar. Mais crucial torna-se o problema, pois, diante da nova legislação, um contingente de alunos chega à quarta série do ensino fundamental sem pelo menos ter iniciado um processo de compreensão da linguagem escrita. O objetivo deste artigo é refletir como os docentes atuam com essa população que já vem com defasagem em sua aprendizagem da leitura e da escrita e necessitam de uma proposta diferenciada de ensino para que possam dar continuidade à sua aprendizagem. Os dados e a análise são de uma pesquisa mais ampla e servem para esclarecer a relação entre a realidade da prática profissional e a eficácia da transmissão do conhecimento da leitura e da escrita.

Palavras-chave: alfabetização, leitura, escrita, mediação, sistema de ensino.

\section{Título em inglês: READING AND WRITING A RIGHT OF ALL ABSTRACT}

For many decades, many failures and evasion from school, especially during the reading and writing learning process, have been indicated as one of the main problems at elementary school. The learning process, even after several educational system changes, still presents a concern about the high rate of pupils who cannot read or write. This issue becomes more crucial, since the new legislation accepts that fourth grade pupils from elementary school have neither initiated their written language comprehension process nor reached the alphabetic hypothesis. The previous stage occurs when pupils are able to read and write graphically what they think or speak, so it is the alphabetic basis comprehension that states a certain knowledge level of this process so that it can be improved. The aim of this paper is a reflection on the educators actuation related to this population with reading and writing problems, about elementary school fourth-graded-pupils who need a different educational offer which will be able to continue their learning. The data and analysis are from a wide research and those can clear up the relation between the practical and professional reality and the efficiency of the knowledge transmission related to the reading and writing.

Index Terms: alphabetization, educational system, mediation, reading, writing. 


\section{Apresentação}

Uma parte da população que ingressa no sistema educacional possui grande dificuldade em acompanhar o processo de ensino, principalmente nas séries iniciais, pois a preocupação em atender à crescente demanda que acompanhou o processo de urbanização do país deixou de lado a qualidade de ensino básico.

As dificuldades de alfabetização das crianças oriundas das classes desprivilegiadas tem sido um problema grave na educação brasileira, desde os primeiros movimentos da democratização do ensino e de ampliação das oportunidades educacionais. Há mais de 40 anos, em nosso país, a evasão entre a $1^{\mathrm{a}}$ e a $2^{\mathrm{a}}$ séries atinge uma taxa próxima dos cinqüenta por cento ${ }^{1}$.

Nos dois últimos anos, algumas Secretarias de Educação adotam o Sistema de Ciclos previsto na nova Lei de Diretrizes e Bases do Ensino Nacional (LDB). A proposta de ciclos representava (e continua representando) uma possibilidade concreta de superar a injustiça do "tudo ou nada" encarnada no sistema seriado e, de certa forma, a organização da escolaridade em ciclos é também uma forma indireta de combater a evasão. Como sabemos, a retenção é a grande vilã da evasão escolar, porque atesta institucionalmente um fracasso que seria do aluno.

Hoje, o sistema educacional já reformulou a proposta de ciclo básico e temos, no ensino fundamental, dois ciclos: o primeiro, da $1^{\mathrm{a}}$ série à $4^{\mathrm{a}}$ série; e o segundo, da $5^{\mathrm{a}}$ série à $8^{\mathrm{a}}$ série. Como conseqüência, temos um contingente de alunos que chegam à $4^{\mathrm{a}}$ série sem o domínio dos recursos básicos da linguagem escrita. Essa pesquisa foi voltada aos alunos com dificuldades de aprendizagem na leitura e na escrita, na quarta série do ensino fundamental.

Neste contexto, a compreensão da natureza da escrita, de suas funções e de seus usos é indispensável ao processo de alfabetização, mas o que se vê comumente, nas salas de aula e nos livros didáticos, é um total desconhecimento do assunto. O processo de alfabetização inclui muitos fatores e quanto mais o professor souber sobre eles, mais condição terá de encaminhar de forma agradável e produtiva o processo de aprendizagem, alguns deles são: o processo de aquisição de conhecimento, o desenvolvimento emocional,

\footnotetext{
1 Taxas de reprovação ao final da $1^{\text {a }}$ série do Ensino Fundamental (IBGE/INEP): 1956: 56,6\%; 1987: 51\%; 1988: 52\%; 1989: 49\%; 1990: 48\%; 1991: 48\%; 1992: 48\%; 1993: 49\%; 1994: 46\%; 1995: 46\%; 1997: 35\%; 1998: $31 \%$.
} 
o processo de integração social, a natureza da realidade lingüística envolvida no momento em que acontece a alfabetização.

Com toda essa base de dados ${ }^{2}$, o Inep (2000) demonstra o escandaloso funil que o sistema reproduz à imagem e semelhança das distorções sociais que foram sendo agravadas nos últimos anos. Outra pesquisa importante, feita pelo Instituto Paulo Montenegro e pela Organização não-governamental (ONG) Ação Educativa, apresentada em 13 de dezembro de 2001, cujos dados ${ }^{3}$ não são animadores.

\section{Pressupostos teóricos de aprendizagem da linguagem escrita}

Primordialmente, alfabetização é a aprendizagem da leitura e da escrita; portanto, é o momento mais importante da formação escolar de uma pessoa, assim como a invenção da escrita foi um dos momentos mais importantes da História da Humanidade, pois, por meio de registros escritos, o saber acumulado pode ser transmitido às demais gerações. Segundo Cagliari (1989, p. 106), a história da escrita pode ser vista no seu conjunto, sem seguir uma linha de evolução cronológica, específica de algum sistema, e pode ser caracterizada por três fases distintas: a pictórica, a ideográfica e a alfabética.

A fase pictórica se distingue pela escrita por meio de desenhos ou pictogramas que aparecem em inscrições antigas, podendo ser vistos de maneira mais elaborada nos cantos "Ojibwa”, da América do Norte, e na escrita asteca. Os pictogramas não estão associados a um som, mas à imagem do que se quer representar. Consistem em representações bem simplificadas dos objetos da realidade. A representação pictográfica era feita em entalhes

\footnotetext{
${ }^{2}$ Até 2001 , demonstra-se que $41 \%$ dos alunos conseguem terminar o ensino fundamental (de $1^{\mathrm{a}}$ a $8^{\mathrm{a}}$ série). O estudo diz ainda que $9 \%$ dos que estavam nessa fase tinham idade superior à correta. Os dados apontam que $21,7 \%$ dos estudantes do ensino fundamental repetiram de série no ano 2000. Os alunos que conseguem chegar ao ensino médio o fazem, em média, em 10,2 anos; dos que atingem essa fase, $26 \%$ não terminam. A distorção entre a série e a idade, apontada por educadores como um dos principais problemas, sobe nesse estágio: $53,3 \%$ estão fora da faixa adequada. Os problemas apontados são: a baixa qualidade da escola pública, o baixo salário dos professores e os custos das famílias para manter os alunos. Em 2000, 35,7 milhões de jovens ingressaram no ensino fundamental em todo o país e, desse total, só 8,4 milhões chegaram ao ensino médio, o que significou uma "evasão" de $77 \%$. Somente 2,7 milhões chegaram ao ensino superior, número que indica uma evasão de quase $68 \%$. Diante desses dados, podemos levantar questões acerca da proposta de ensino, de sua qualidade e, provavelmente, de implicações como a dificuldade de aprender a ler e a escrever, já que o número de alunos que chega ao ensino médio é insignificante, comparado ao número de alunos que ingressam no ensino fundamental.

${ }^{3}$ Os primeiros dados do Indicador Nacional de Alfabetismo Funcional (Inaf). Os dados, resultado da pesquisa realizada pelo Instituto Brasileiro de Opinião Pública e Estatística (Ibope), mostram que 9\% da população brasileira, na faixa de 15 a 64 anos, encontra-se na situação de analfabetismo. As pessoas alfabetizadas, por sua vez, foram classificadas em três níveis: $31 \%$ da população estudada foi classificada no Nível 1 de alfabetismo (consegue retirar uma informação explícita apenas em textos muito curtos); 34\%, no Nível 2 (consegue também localizar uma informação não explícita em textos de maior extensão); e 26\%, no Nível 3 de alfabetismo (é capaz de ler textos mais longos, localizar mais de uma informação e estabelecer relações entre diversos elementos do texto). Para realizar a pesquisa, o Ibope entrevistou duas mil pessoas, com idade de 15 a 64 anos, em todo o Brasil, pertencentes a todas as classes sociais. Outro dado interessante, levantado pelo estudo, é que $37 \%$ dos brasileiros não lêem nada no trabalho, e $41 \%$ deles não escrevem nada. A definição sobre o que é analfabetismo vem sofrendo revisões significativas ao longo das décadas. Em 1958, a Organização das Nações Unidas para a educação, a ciência e a cultura (Unesco) definia como alfabetizado uma pessoa capaz de ler e escrever um bilhete simples. Vinte anos depois, a Unesco adotou o conceito de analfabetismo funcional. É considerada alfabetizada funcional toda pessoa capaz de utilizar a leitura e a escrita para fazer frente às demandas de seu contexto social, bem como usar suas habilidades para continuar aprendendo e desenvolvendo-se ao longo da vida.
} 
de madeira e em monumentos de pedra. Esses recursos variavam de cultura para cultura, seguindo o seu desenvolvimento. Além do sistema pictográfico, outros precursores da escrita são os recursos de identificação mnemônicos, como os símbolos heráldicos e os símbolos usados por indígenas, para registrarem o tempo. Nesse estágio, a escrita caracteriza-se pela correspondência aproximada entre símbolo pictográfico e a imagem de um objeto, de uma pessoa, ou de uma frase. Tais sistemas têm origem no Oriente, há aproximadamente três mil anos a.C., sendo alguns de seus exemplos a escrita suméria e a egípcia. De acordo com Gelb (1982, p. 38), surgem, assim, na Mesopotâmia, as escritas cuneiformes, as quais utilizam signos convencionais, muitas vezes, o figurativo em seus aspectos externos.

Além dessas, a fase ideográfica se caracteriza pela escrita por meio de desenhos especiais, chamados ideogramas. Esses desenhos foram, ao longo de sua evolução, perdendo alguns dos traços mais representativos das figuras retratadas e tornaram-se uma simples convenção da escrita. As escritas ideográficas mais importantes são a egípcia, a suméria, as escritas da região do mar Egeu (a cretense) e a chinesa. Novos progressos se realizam até que o ideograma não mais evoque uma frase ou uma imagem da palavra, e a mesma passe a ser representada do ponto de vista de seu conteúdo semântico.

Segundo Auzias e Ajuriaguerra (1986, p. 27), de sintética, a escrita torna-se analítica. A fase alfabética se caracteriza pelo uso de letras que tiveram sua origem nos ideogramas, mas perderam o valor ideográfico, assumindo uma nova função de escrita: a representação puramente fonográfica. O ideograma perdeu seu valor pictórico e passou a ser, simplesmente, uma representação fonética. Foi o silabário fenício que os gregos tomaram emprestado para a base de sua escrita. O que era feito esporadicamente pelos fenícios, isto é, a colocação da vogal depois da consoante, firmou-se entre os gregos como norma. Passou-se, assim, da escrita silábica para a escrita alfabética. A descoberta do alfabeto ocorre no século X a.C.. Depois da descoberta desse sistema, segundo Gelb (1982, p. 56), nenhuma inovação significativa ocorreu na história da escrita.

Embora haja inúmeras variedades do alfabeto no mundo, as quais apresentam diferenças formais externas, todas ainda usam os mesmos princípios estabelecidos pela escrita grega. Na verdade, a invenção da escrita alfabética é uma "descoberta", pois, quando o homem começou a usar um símbolo para cada som, apenas operou conscientemente o conhecimento da organização fonológica de sua língua. Com relação a isso, é interessante ressaltar o que afirma Vygotsky (1984, p. 131), a partir dos trabalhos 
que realizou com crianças: para aprender a escrever, a criança precisa fazer uma descoberta básica, a de que pode desenhar não apenas objetos, mas também a própria fala.

A escrita sempre foi uma maneira de representar a memória coletiva, religiosa, científica, mágica, política, artística e cultural de uma sociedade. A escrita tem como objetivo a leitura, pois é por meio dela que se efetiva a comunicação desejada. Ler é uma atividade extremamente complexa e envolve problemas não só semânticos como culturais, ideológicos, filosóficos e fonéticos. A leitura é a realização do objetivo da escrita; quem escreve, faz isso para ser lido. A leitura vai operar justamente nesse universo. Às vezes, ler é um processo de descoberta, tal como a busca do saber científico; portanto, dever ser construído individualmente, segundo Cagliari:

A leitura é uma atividade profundamente individual e duas pessoas dificilmente fazem uma mesma leitura de um texto, mesmo científico. Ao contrário da escrita, que é uma atividade de exteriorizar o pensamento a leitura é uma atividade de assimilação de conhecimento, de interiorização, de reflexão. (CAGLIARI, 1989, p. 150)

Os signos lingüísticos atuam pela convencionalidade social. A escrita atua pela convencionalidade da representação gráfica dos signos, e a leitura também possui sua convencionalidade guiada não só pelos elementos lingüísticos, mas também pelos elementos culturais, ideológicos e filosóficos do leitor. Ou seja, toda leitura tem um aspecto de decifração e de decodificação; essas atividades devem possuir um equilíbrio entre dois aspectos (significado/significante), caso contrário, haverá o risco de destruir a linguagem humana naquilo que possui como princípio fundamental. A relação leitura e escrita mostra-nos que o processo é complexo, possuindo inúmeras facetas, as quais têm gerado e encaminhado diferentes propostas metodológicas ${ }^{4}$, de acordo com seus pressupostos.

\section{Um novo paradigma: Psicogênese da Língua Escrita}

Os anos 80 assistiram, no Brasil e na América Latina, a um crescente interesse pelo tema alfabetização. As idéias de Emilia Ferreiro, rapidamente difundidas, contribuíram enormemente nestes debates.

A citada psicóloga argentina, ao estudar a gênese psicológica da compreensão da língua escrita na criança, desvenda a "caixa-preta" dessa aprendizagem, demonstrando

\footnotetext{
${ }^{4}$ A chamada "Escola Nova", seus objetivos e métodos são consequiência das mudanças ocorridas na sociedade, as quais solicitam da estrutura escolar novas propostas de ensino. Os métodos tradicionais são questionados, pois partem do pressuposto de que a criança é um homem em miniatura, cabendo à educação transmitir a cada nova geração, como uma "doação", os conhecimentos acumulados pela humanidade. A preocupação com o problema não é recente, nem exclusiva de um ou outro país, conforme atestam as várias publicações sobre o assunto. Em decorrência disso, acentuam-se as investigações sobre o assunto, que constituíram a base para novas reformulações metodológicas.
} 
como são os processos existentes nos sujeitos dessa aquisição; até que uma proposta empírica dessa natureza fosse feita, o tema da aprendizagem da escrita era considerado apenas uma técnica dependente dos métodos de ensino. Para a citada educadora (1986), as crianças interpretam o ensino que recebem, transformando a escrita convencional dos adultos. Sendo assim, produzem escritas diferentes e estranhas. Essas transformações descritas por Ferreiro são brilhantes exemplos dos esquemas de assimilação piagetianos. $\mathrm{O}$ professor ensina, por exemplo, a palavra GATO, e alguns de seus alunos escrevem GO, ou AO, ou GT. O que Ferreiro desvenda é a razão dessas transformações e a lógica empregada pela criança, ou os processos psicológicos que produzem tais condutas. A escrita produzida é fruto da aplicação de esquemas de assimilação ao objeto de aprendizagem (a escrita), formas utilizadas pelo sujeito para interpretar e compreender o objeto.

Do nosso ponto de vista, há a constituição de uma forma nova de olhar para a escrita infantil, muito diferente daquela de longa tradição escolar. Os erros sistemáticos, regulares e recorrentes chamam a atenção da pesquisadora e levam-na a se perguntar se não seriam indícios de compreender a linguagem escrita. Partindo, então, deste pressuposto de que as crianças adquirem o conhecimento da linguagem escrita porque, em interação com esse objeto, aplicam a ele esquemas sucessivamente mais complexos, decorrentes do seu desenvolvimento cognitivo, o desdobramento que segue é o estabelecimento de diferentes momentos de aquisição, articulados em níveis, fases ou períodos. Esses ocorrem em graus crescentes de complexidade e aproximação da escrita convencional.

[...] Pretendemos demonstrar que a aprendizagem da leitura, entendida como questionamento a respeito da natureza, função e valor desse objeto cultural que é a escrita, inicia-se muito antes do que a escola imagina, transcorrendo por insuspeitados caminhos. Que, além dos métodos, dos manuais, dos recursos didáticos, existe um sujeito que busca a aquisição de conhecimento, que se propõe problemas e trata de solucioná-los, segundo sua própria metodologia... Insistiremos sobre o que se segue: trata-se de um sujeito que procura adquirir o conhecimento, e não simplesmente de um sujeito disposto a adquirir uma técnica particular. Um sujeito que a psicologia da lecto-escrita esqueceu [...]. (FERREIRO; TEBEROSKY, 1985, p. 11)

Ao ingressar na série em que começa o ensino sistemático das letras, a criança já detém uma grande competência lingüística. Na ação equivocada da escola, têm origem dois desvios: o primeiro deles é tratar a aquisição da escrita como se esta fosse idêntica à apropriação da fala, e o segundo é que o modelo de aprendizagem da língua oral, que a maioria dos métodos de alfabetização reproduz, sustenta-se num conhecimento já ultrapassado. Esses conhecimentos, anteriores ao trabalho de Chomsky, são assim sintetizados por Emilia Ferreiro: 
[...] a progressão clássica que consiste em começar pelas vogais, seguidas da combinação de consoantes labiais com vogais, e a partir daí chegar a formação das primeiras palavras por duplicação dessas sílabas, e, quando se trata de orações, começar pelas declarativas simples, é uma série que reproduz bastante bem a série de aquisição da língua oral, tal como ela se apresenta vista "do lado de fora" (isto é, vista desde as condutas observáveis, e não desde o processo que engrena essas condutas observáveis). Implicitamente, julgava-se ser necessário passar por essas mesmas etapas quando se trata de aprender a língua escrita, como se essa aprendizagem fosse uma aprendizagem de fala. (FERREIRO; TEBEROSKY, 1985, p. 24)

Como conseqüência, quando o modelo de aquisição da língua oral é utilizado para a escrita, o critério "falar bem", ou ter "boa articulação", é considerado importante para aprender a escrever. Reaprender a produzir sons da fala, como condição necessária para escrever, baseia-se assim, em dois falsos pressupostos. O primeiro deles é que uma criança, aos seis ou sete anos, não é capaz de distinguir fonemas de sua língua; hipótese negada pelo gosto que as crianças dessa idade têm pelos jogos verbais. A segunda falácia é a concepção da escrita como forma de transcrição da fala. Nenhuma escrita, examinada nas relações que mantém com o código oral, realiza a transcrição fonética da língua oral. Ou seja, as condutas escritas de um aprendiz não são o mero resultado daquilo que o professor ensina, já que existe um processo de construção desse conhecimento, que nem sempre coincide com aquilo que está sendo ensinando e para observar esse processo de construção, temos que voltar nossa atenção para as eventuais hipóteses da criança e verificar conduta espontânea no seu registro gráfico.

Neste sentido, as tarefas incluíram a escrita do próprio nome, do de algum amigo ou membro da família; a escrita de palavras muito freqüentes no início da alfabetização; o contraste das situações entre desenhar e escrever; e a escrita de outras palavras ainda desconhecidas para a criança. Por que pedir às crianças para escreverem algo que ainda não aprenderam? Ferreiro justifica a proposta pela razão de que a escrita espontânea, produzida antes do ensino sistemático, traz os mais claros indicadores das explorações infantis para compreender a natureza do processo.

Quando a criança escreve tal com acredita que poderia ou deveria escrever certo conjunto de palavras, está nos oferecendo um valiosíssimo documento que necessita ser interpretado para poder ser avaliado [...]. (FERREIRO, 1987, p. 16)

Uma criança costuma rabiscar, utilizar lápis e papel, se tiver oportunidade para isso. Essas primeiras escritas nunca foram adequadamente consideradas, sendo vistas apenas como rabiscos ou garatujas sem importância. Portanto, na concepção de Emilia Ferreiro, a criança, a princípio, aprende elaborando uma série de hipóteses sobre a construção da 
escrita, através, não só de vivências externas, mas também internas, baseando-se em critérios, segundo sua própria lógica.

Assim, a criança passa por "níveis" de aprendizagem, ou seja, há uma série de modos de representação que precedem à representação alfabética da linguagem e que sucedem em certa ordem: vários modos de representação, alheios a qualquer busca de correspondência entre a pauta sonora de uma emissão e a escrita; depois, modos de representação silábicos (com ou sem valor sonoro convencional); e modos de representação silábico-alfabéticos que procedem regularmente à aparição da escrita regida pelos princípios alfabéticos. De acordo com a teoria, toda criança passa por fases ${ }^{5}$ até que esteja alfabetizada.

\section{Alguns dados da pesquisa ${ }^{6}$}

O universo desta pesquisa, realizada em 2004, envolve os alunos que estão cursando o quarto ano do ensino fundamental e que se apresentam na base alfabética da linguagem escrita, estejam, ou não, em idade compatível com a série freqüentada.

A amostra foi selecionada de acordo com as características do tema em questão e analisada em dois momentos: no primeiro, apenas a análise do tipo de escrita do aluno foi feita; e, no segundo, uma análise mais completa, envolvendo os seguintes dados: histórico dos alunos e queixas dos pais, dos professores e dos alunos.

Foi feito um levantamento de dados na Secretaria da Educação do Município de Osasco sobre os alunos matriculados na $1^{\mathrm{a}}$ série do ensino fundamental de Osasco, no ano de 2003, quando havia: 188 classes com 6.835 alunos, e 171 classes de $4^{\mathrm{a}}$ série com 6.428 alunos. Já encontramos uma evasão de 5,95\%.

Outro levantamento realizado sobre os alunos das $4^{\mathrm{a}}$ séries com dificuldades na aprendizagem da linguagem escrita, na escola que será denominada $\mathrm{A}$, nos forneceram os seguintes resultados: há um total de 316 alunos de $4^{\text {a }}$ séries. Destes, 17\% (54 alunos) não conhecem a linguagem escrita correspondem a $17 \%$ e, ainda, existem duas classes na escola, a I e a J, chamadas de classes de aceleração, formadas por alunos que não sabem ler e escrever.

\footnotetext{
${ }^{5}$ Os níveis conceituais lingüísticos são: Nível Pré-Silábico, Silábico, Silábico-Alfabético e Alfabético. Cada um desses níveis possui características específicas que devem ser acompanhadas pelo docente, para que esse possa trazer atividades desafiadoras, fazendo com que o aluno consiga avançar em suas hipóteses e chegar ao Nível Alfabético, no qual consiga ler e escrever graficamente aquilo que pensa e fala, possuindo compreensão da logicidade da base alfabética, o conhecimento do valor sonoro convencional de todas ou de grande parte das letras, distinção de letra, sílaba, palavra e frase. Se nem sempre escreve de modo correto, o desafio será, então, caminhar à convencionalidade, em direção às correções ortográfica e gramatical.

${ }^{6}$ Para maiores informações e detalhes acerca desta pesquisa, entrar em contato com a autora.
} 
Destas classes, foram sorteados aleatoriamente 20 alunos para sondagem da escrita. Entramos em contato com as professoras que estavam atuando nessas classes e duas participaram desta pesquisa, através de entrevista gravada, a qual nos trouxe dados importantes para que pudéssemos compreender a situação desses alunos e dos docentes.

As professoras responderam aos nossos questionamentos com naturalidade, mostrando a angústia que sentiam por estarem diante de uma realidade complexa e diante da qual não sabiam como se conduzir. Tinham boa vontade, mas isso não era o suficiente, pois são necessários um acompanhamento e uma orientação pedagógica clara e definida, para uma clientela específica.

Conforme pudemos verificar na fala das professoras, elas sentem-se muito desamparadas, sem orientação e declaram uma falta de preparo para atuarem diante dessa realidade. Além disso, observamos que, trabalhar em sala de aceleração, não tinha sido opção das mesmas.

Podemos verificar que as professoras entrevistadas levantaram aspectos que são importantes para a aprendizagem em geral, demonstrando que é necessário que o professor conheça seu aluno, saiba qual o conhecimento que esse já possui, já que o aluno traz consigo um conhecimento que deve ser considerado pela escola, para poder desenvolver o que é importante no processo de aprendizagem da linguagem escrita. Percebem também o quanto é importante resgatar a individualidade do aluno, no contexto da sala de aula.

Além disto, por meio destas professoras, soubemos que elas apontam questões importantes, como o trabalho diferenciado que deve ser feito nessas classes, assim como a necessidade de uma proposta diferenciada de alfabetização, pois as tradicionais já não foram suficientes para que os alunos conseguissem aprender. No entanto, não conseguem ainda trabalhar com novas propostas, pois, em seus relatos, demonstram estar voltadas, em alguns momentos, para o ensino tradicional, e, em seguida, para as questões que envolvem a problemática dos alunos, não conseguindo desenvolver uma proposta adequada de ensino.

\section{Algumas considerações}

Em sociedades letradas como a nossa, a comunicação através da escrita está presente em muitas situações quotidianas: nas placas de ruas e de ônibus, em letreiros, em anúncios, em lojas, nas embalagens dos produtos que utilizamos, em folhetos informativos, na televisão, no cinema, nos livros, nos jornais e nas revistas. 
A criança, especialmente a do meio urbano, não convive com tudo isso sem interagir com a língua escrita. Ela observa, pensa, faz perguntas, formula hipóteses, experimenta e tira suas próprias conclusões. Por isso, não é possível encarar a aprendizagem da leitura e da escrita como um momento estanque e isolado na vida do sujeito, uma simples ação sobre o alfabeto, desligada de sua realidade.

E, assim, nosso aluno vai sendo submetido a práticas, as quais não levam em conta as experiências anteriores ao seu ingresso na escola, o processo interno que possibilitou as primeiras aprendizagens, e o prazer que deve fazer parte de todo trabalho, principalmente, do ato de aprender.

É certo que um número inadmissível de alunos vem fracassando no seu propósito de se beneficiarem naquilo que deveria constituir a função primordial da escola, a formação do leitor. Muitos não chegam sequer a "decifradores"... Isso ocorre não porque sejam deficientes, inferiores ou menos inteligentes, mas sim, porque, do seu cotidiano, não fazem parte as experiências que possibilitam ao outro grupo o sucesso desejado.

O domínio da língua tem estreita relação com a plena participação social, pois é por meio dela que o homem se comunica, tem acesso à informação, expressa e defende pontos de vista, compartilha a visão de mundo e reproduz conhecimentos. Assim, um projeto educativo comprometido com a democratização social e cultural, atribui à escola a função e a responsabilidade de garantir aos seus alunos o acesso aos saberes lingüísticos necessários para o exercício da cidadania, direito inalienável de todos.

Para aprender a ler e a escrever é preciso pensar sobre a escrita, pensar sobre o que a escrita representa e como ela representa graficamente a linguagem. Para isso, é necessário compreender a elaboração do pensamento do ser que aprende; entender, por exemplo, como funciona o pensamento da criança quando está aprendendo a ler e escrever, o que leva o aprendiz à reconstrução do código lingüístico.

Vygotsky e seus seguidores analisam a linguagem como um conjunto de símbolos com caráter histórico e social e enfatizam a importância da informação e da interação lingüística para a construção do conhecimento. A partir das investigações desses estudiosos, o educador tem condições de perceber claramente o processo de apropriação de conhecimento pelo aprendiz, ou seja, como se dá a aprendizagem, e mediar a construção desse conhecimento, nos momentos em que o aprendiz necessita, efetivamente, de uma intervenção pedagógica.

Quando o professor conhece as concepções que o aluno desenvolve a respeito da língua escrita, pode tornar-se um mediador, propondo atividades e questionamentos que 
levem o aluno a "desestruturar o pensamento", isto é, duvidar de suas idéias, colocar em conflito as suas certezas sobre os símbolos escritos e, comparando e refletindo, elaborar uma nova hipótese lingüística. Assim, através de conflito, assimilação e acomodação, o educador chega à hipótese alfabética e, depois, passo a passo, busca a convencionalidade ortográfica e gramatical.

O processo de ensino e de aprendizagem para a alfabetização deve ser organizado, de modo que a leitura e a escrita sejam desenvolvidas por intermédio de uma linguagem real, natural, significativa e vivenciada, principalmente para os alunos que fizeram parte desta pesquisa, pois, se eles tivessem, pelo menos, chegado ao nível alfabético, teriam já vencido os obstáculos conceituais para a compreensão da escrita. O que esses alunos teriam alcançado não significaria a superação de todos os problemas, pois haveria, ainda, o alcance da legibilidade da escrita produzida, mas um amplo conteúdo já teria sido dominado.

Com os dados obtidos nesta pesquisa pudemos verificar que há necessidade de se repensar o ensino da leitura e da escrita, principalmente para os alunos que se encontram nessa situação, pois os mesmos já possuem um comprometimento em sua aprendizagem, que repercute em suas relações familiares, emocionais e no próprio ambiente escolar.

Outro dado importante é a necessidade da escola rever o processo de aprendizagem da leitura e da escrita, como está sendo encaminhado, bem como escolher professores que estejam capacitados para atuar nesse processo, e principalmente, nessas classes formadas com alunos defasados em sua aprendizagem, as quais devem ter uma proposta de ensino diferenciado. O sistema de ensino deveria garantir aos docentes que irão atuar com essas classes orientação pedagógica adequada e acompanhamento específico, já que deverão atuar de maneira diversificada.

Este estudo demonstra que a aprendizagem da leitura e da escrita ainda é um problema crucial no sistema de ensino, pois evidencia o grande número de alunos que estão matriculados na escola e que são freqüentes não conseguem compreender como se dá esse processo e possuem dificuldades em ler e escrever. Aponta, também, a dificuldade encontrada pela escola em trabalhar com esses alunos e as questões que envolvem a atuação dos professores em seu dia-a-dia levados a atuar em classes de aceleração. Esses professores deveriam ter uma proposta diferenciada, com acompanhamento pedagógico específico, pois atendem a uma clientela que carrega uma história de fracasso em sua aprendizagem. É importante salientar que esses alunos, na maioria dos casos, são alunos 
capazes, necessitando apenas uma oportunidade para poderem desenvolver uma aprendizagem significativa, a qual é direito de todos: ler e escrever.

\section{Referências bibliográficas}

AUZIAS, M., AJURIAGUERRA, J. (1986). Les fonctions culturelles de l'écriture et les conditions de son développement chez l'enfant. Enfance, 2-3, 145-167.

AZEVEDO, Cleomar. (1994). A prática do professor alfabetizador: algumas considerações. Dissertação (Mestrado) - FEUSP.

Paulo: Vetor.

(2003). As emoções no processo de alfabetização e a atuação docente. São

CAGLIARI, Luiz Carlos. Alfabetização e lingüística. São Paulo: Scipione, 1989.

FERrEIRO, Emilia; TEBEROSKY, Ana. (1985). Psicogênese da língua escrita. Porto Alegre, RS: Artes Medicas.

FERREIRO, Emilia (1987). Reflexões sobre alfabetização. São Paulo: Cortez. . (1986). Alfabetização em processo. São Paulo: Cortez.

GELB, Ignace Jay (1982). Historia de la escritura. 2. ed. Madrid: Alianza Editorial.

VYGOTSKY, Lev Semionovitch. (1984). A Formação Social da Mente. São Paulo: Martins Fontes. . (1993). Pensamento e Linguagem. São Paulo: Martins Fontes.

\section{Autora}

\section{Cleomar Azevedo}

Professora Pesquisadora do Centro Universitário Fieo - UNIFIEO, Doutora em Psicologia Social pela Pontifícia Universidade Católica de São Paulo (PUC-SP), Professora do curso de Mestrado em Psicologia Educacional e do curso de Lato Sensu em Psicopedagogia, nas disciplinas de Fundamentos da Psicopedagogia, Didática, Psicologia da Educação, Prática de Ensino, Psicogênese da Língua Escrita, Psicodrama e Psicolingüística.

Telefones: 5017-1357 - 7132-8224 (cel).

Endereço Profissional: Av. Franz Voegeli, 300 - Vila Yara - Osasco - SP

Endereço Residencial: Av. Leonardo da Vinci, 211, ap. 63 - Vila Guarani - SP, 04313-000

Cleomar.Azevedo@uol.com.br 


\section{Como citar este artigo:}

AZEVEDO, Cleomar. Ler e escrever: um direito de todos. Revista Moçambras: acolhendo a alfabetização nos países de língua portuguesa, São Paulo, ano 1, n. 2, 2007. Disponível em: <http://www.mocambras.org>. Publicado em: março 2007. 